American Journal of Infectious Diseases 6 (1): 8-12, 2010

ISSN 1553-6203

(C) 2010 Science Publications

\title{
Cytomegalovirus Immunity in Pregnancy in South of Iran
}

\author{
${ }^{1}$ Abdolreza Sotoodeh Jahromi, ${ }^{2}$ Mahin Jamshidi Makiani, ${ }^{1}$ Mohammad Reza Farjam, \\ ${ }^{3}$ Abdolhosin Madani, ${ }^{4}$ Malihe Amirian, ${ }^{2}$ Tasnim Eqbal Eftekhri and ${ }^{2}$ Sima Hamidipour \\ ${ }^{1}$ Department of Immunology, Jahrom University of Medical Sciences, Jahrom, Iran \\ ${ }^{2}$ Department of Internal Medicine, Hormozgan University of Medical Sciences, Banddar Abbas, Iran \\ ${ }^{3}$ Department of Hygiene, Hormozgan University of Medical Sciences, Banddar Abbas, Iran \\ ${ }^{4}$ Department of Gynecology, Hormozgan University of Medical Sciences, Banddar Abbas, Iran
}

\begin{abstract}
Problem statement: Fetal loss and abortion are responsible for significant emotional distress for couples desiring children. There are many documents which support the role of some certain asymptomatic infections such as Cytomegalovirus (CMV) in spontaneous abortion. This study was aimed to evaluate the prevalence of seropositivity for CMV IgG and IgM in women with abortion and compare it with normal women with no previous history of abortion. Approach: This case-control study was carried out in Shariatee hospital of Hormozgan University of medical sciences, during 20032004. A number of 250 women with definite diagnosis of previous abortion and 200 matched women with normal full term delivery and negative history of miscarriage as controls were studied as case and control groups. Serum samples were obtained from participants and a demographic questionnaire was also filled for each of them. .All serum samples were then tested using ELISA method for detection of anti-CMV IgM and IgG Antibodies. Data was analyzed, using SPSS software (chi square and t-test). Results: The average age was $25.6 \pm 7.6$ years in case group and $25.3 \pm 6.5$ years in control group. The number and percentage for CMV-IgG was $235(94 \%)$ and $150(75 \%)$ in case and control groups, respectively (p-value $=0.0001)$. In case group $13(5.2 \%)$ women were positive for CMV-IgM, while no positive sample was detected in control group $(\mathrm{p}$-value $=0.0001)$. Conclusion: This study showed higher prevalence of seropositivity for CMV in women with spontaneous abortion comparing to women with normal full term delivery and suggest that cytomegalovirus plays a significant role in abortion.
\end{abstract}

Key words: Cytomegalovirus, abortion, seropositivity

\section{INTRODUCTION}

Human Cytomegalovirus (CMV) is the most common cause of congenital malformation resulting from viral intrauterine infection in developed countries (Demmler, 1991; Gaytant et al., 2002; Stagno et al., 1986).

Up to $15 \%$ of intrauterine CMV infections result in symptomatic congenital disease at birth and 10 to $15 \%$ of those born with asymptomatic congenital CMV will develop significant clinical sequelae in infancy (Boppana et al., 1992; Dahle et al., 2000; Fowler and Boppana, 2006).

Some researches have conducted to determine the role of (CMV) infection in pregnancy and some of them showed significant relation between this infection and spontaneous abortion (Enders et al., 2001; Cook et al., 1993; Luerti et al., 1983). There are also evidences which suggest that CMV will lead to complicated pregnancies (Hammouda et al., 1993).

The usefulness of prenatal testing for CMV has been questioned due to the absence of clearly effective intervention (Hagay et al., 1996) however, there is a need for a low-risk, noninvasive diagnostic test. Laboratory methods are required to diagnose acute CMV infections since most present nonspecific symptoms. The presence of CMV-specific Immunoglobulin $\mathrm{M}$ ( $\operatorname{IgM}$ ) may not be indicative of primary infection, since it is also produced during reactivation and re infection (Nielsen et al., 1988). IgG antigen avidity has been used to clarify primary or non primary infections by measuring the binding affinity of $\mathrm{IgG}$ antibodies. IgG of low avidity are produced at the onset of infections and subsequent maturation of the antibody increases its avidity over time. The use of IgG testing has been shown to be useful for

Corresponding Author: M. Jamshidi Makiani, Department of Internal Medicine, Hormozgan University of Medical Sciences, Banddar Abbas, Iran 
distinguishing primary and non-primary CMV infections (Bodeus et al., 1998; Grangeot-Keros et al., 1997; Lazzarotto et al., 1997).

The aim of this study was to determine the seroprevalence of $\mathrm{CMV}$ in our local pregnant population to see the effect of age, previous abortion and parity on its seroprevalence.

\section{MATERIALS AND METHODS}

We conducted a case-control study in the delivery population of University Hospital (Hormozgan province, Iran) between Feb. 2003-Jun. 2004, to investigate whether prevalence of AntiCytomegalovirus antibodies (IgM and IgG) in two groups of women with spontaneous abortion and without history of abortion to determine a relation between the role of seropositivity for this virus and abortion as well as factors which might have an influence in the pathogenesis of these infections.

Cases were 250 women who were identified with spontaneous abortion by gynecologist during the study period and control group consisted of 200 asymptomatic women with no history of abortion and full term delivery who were referred to Hormozgan University Hospital.

All subjects gave written consent for obtaining their blood samples according to research purposes. Whole blood samples were collected from all women in both groups. Serum separation was done by centrifuging of whole blood samples at $2000 \times \mathrm{g}$ for 20 min.

A structured interview using a standard maternal questionnaire was administered by trained interviewers with the women at their first visit. Questions were asked about the following: age, parity, gynecologic and medical history of abortion, residence and socioeconomic status.

The ELISA technique was performed using kits intended for estimating concentration of specific CMV-IgM and CMV-IgG markers. The kits were purchased from Sigma Diagnostics (USA), the techniques were performed according to the manufacturer's instructions.

Data analysis: For assessment of risk factors for CMV infection (exposure), characteristics of case patients and control subjects were examined using a two-sample Student t test. Cross-tabulation and chi-square or Fisher exacts tests were used to examine the relationship between variables using a $95 \%$ confidence interval as a measure of association.
Also, univariate odds ratios 0.19 and $95 \%$ Confidence Intervals (CIs) using the exact method were calculated.

All data analyses were performed using SAS 8 statistical software (SAS Institute, Inc, Cary, NC).

\section{RESULTS}

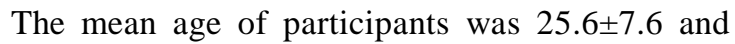
$25.3 \pm 6.5$ years in the pregnant women with abortion and with full term delivery, respectively. The mean gestational age was 8 weeks and the mean parity was 2.4 children in abortion group. The mean gestational age was 38 weeks and the mean parity was 2.1 children in full term group. There was no significant difference between age and parity in two groups $(\mathrm{p}=0.60)($ Table 1$)$.

According to prevalence of seropositivity for CMV antibodies, about $88.8 \%$ of the subjects were divided in abortion and $75 \%$ with full term delivery as it is shown in (figure1) and the results of serologic assay we can divide participants in to 4 groups. Group 1: women with negative serology for $\operatorname{IgG}$ and $\operatorname{IgM}$ antibodies, we had only $(6 \%)$ in abortion and $(25 \%)$ in full term delivery group. Group 2 women with IgM seropositivity without positive serology for IgG antibody, abortion group had only $5.2 \%$, and $\operatorname{IgM}$ was not detected in the full term delivery group. Group 3: women with positive serology for IgG and negative for IgM antibodies, we had detected in $(88.8 \%)$ of abortion groups and in $(75 \%)$ of full term delivery group. Group 4; women with positive serology for IgG and IgM antibodies, while at the same time that no one was in abortion group and full term delivery group (Table 2).

Table 1: Baseline data of case and control groups*

\begin{tabular}{llll}
\hline Variables & Cases $\mathrm{n}=250$ & Controls $\mathrm{n}=200$ & $\mathrm{p}$-value \\
\hline Age (year) & $25.6 \pm 7.6$ & $25.3 \pm 6.5$ & 0.600 \\
Residence city & $208(83.2 \%)$ & $150(75.0 \%)$ & 0.030 \\
Village & $42(16.8 \%)$ & $50(25.0 \%)$ & \\
\hline *. Data are presented as $\mathrm{n}(\%)$ or mean + standard deviation &
\end{tabular}

Table 2: Distribution of immunity among abortion and full term delivery groups

\begin{tabular}{|c|c|c|c|c|}
\hline Immunity & $\begin{array}{l}\text { Full term } \\
\text { delivery } \\
\mathrm{N}(\%)\end{array}$ & $\begin{array}{l}\text { With } \\
\text { abortion } \\
\mathrm{N}(\%)\end{array}$ & $\begin{array}{l}\text { Odds } \\
\text { ratio }\end{array}$ & $\mathrm{p}$-value \\
\hline IgG(-) IgM(-) & $50(25 \%)$ & $15(6 \%)$ & 5.22 & 0.001 \\
\hline $\operatorname{IgG}(-) \operatorname{IgM}(+)$ & 0 & $13(5.2 \%)$ & - & 0.001 \\
\hline $\operatorname{IgG}(+) \operatorname{IgM}(-)$ & $150(75 \%)$ & $222(88.8 \%)$ & $\begin{array}{l}0.37 \\
(\text { CI } 0.22-0.62)\end{array}$ & 0.001 \\
\hline $\operatorname{IgG}(+) \operatorname{IgM}(+)$ & 0 & 0 & - & - \\
\hline Total & 200 & 250 & & \\
\hline
\end{tabular}

OR: CI 95\% 
There was no statistically significant relationship between CMV IgM or $\operatorname{IgG}$ seropositivity and parity neither in patients with previous abortion nor with age of the patients with exception in women who had a recent abortion. Women in seronegative $\operatorname{IgG}$ group were younger in comparison with seropositive $\mathrm{IgG}$ $(\mathrm{p}=0.04)$.

\section{DISCUSSION}

CMV is the most common congenital infection and its incidence has been estimated to be between 0.2$2.2 \%$ of all live births in different parts of the world (Ross et al., 2006). This study found the prevalence of seropositivity in $75 \%$ of asymptomatic women with no history of abortion.

According to the results of serologic assay we can divide participants in to 4 groups.

Group 1: Women with negative serology for $\operatorname{IgG}$ and IgM antibodies, they were not contaminated with CMV and were susceptible to infection (primary infection). In this situation there is a risk for transmission of the virus to the fetus during the pregnancy (Enders et al., 2001). It is indicated that prevalence of CMV antibodies was high in pregnant women in south of Iran and a small percent $(6 \%$ in abortion group and $25 \%$ in full term delivery group) of these women were sensitive to CMV infection till reproductive ages that in other studies it was related to some extent to socioeconomic status and geographic location.

Group 2: Women with IgM seropositivity without positive serology for $\operatorname{IgG}$ antibody. These women were considered acutely contaminated with CMV. They were also asymptomatic and indicated the substantial prevalence of infection in the local population (Wreghitt et al., 2003). Only 5.2\% were IgM positive, and the full term delivery group was not positive for IgM. Abortion group and full term delivery groups were significantly different in $\operatorname{IgM}$ seropositivity $(\mathrm{p}=0.00001)$, also primary infection was suspected in abortion group but microbiologic and histologic studies were needed to confirm the infection in fetuses (Collient et al., 2004).

Group 3: Women with positive serology for $\operatorname{IgG}$ and negative for IgM antibodies, these women were considered immune and their primary infection with CMV was assumed to have been taken place before the current pregnancy. CMV IgG antibody was detected in $(88.8 \%)$ of abortion groups and $(75 \%)$ of full term delivery group without IgM seropositivity. This revealed that most of patients in abortion group and full term delivery group were immune against primary CMV infection.

Group 4: Women with positive serology for $\operatorname{IgG}$ and IgM antibodies, at the same time. These women were considered to be possibly infected with CMV during the current pregnancy or a chronic infection which can be confirmed by IgG avidity test because antibody binds to the antigen with less avidity during acute infection than chronic infection (Wreghitt et al., 2003), that no one was in abortion group and full term delivery group.

According to these results we understood prevalence of CMV seropositivity in south of Iran was high but we couldn't conclude there was a relationship between CMV infection and spontaneous abortion.

Most of the patients in abortion group and full term delivery group were immune against CMV and only $6 \%$ in abortion group and $25 \%$ in full term delivery group were sensitive to CMV infection and CMV maternal seropositivity being associated with less severe fetal involvement and maternal immunity plays a protective role in this setting (Fowler et al., 2003). A cohort study has shown maternal immunity prior to conception is highly protective against congenital CMV infection and usual acquired immunity in course of CMV results in $69 \%$ reduction of the risk of congenital CMV infection in future pregnancies (Fowler et al., 2003).

Also primary CMV infection in this study only $5.2 \%$ in abortion group but some surveys demonstrate that IgM can be found frequently in the serum of normal pregnant women without any influence on the pregnancy outcome (Lazzarotto et al., 2004), and there was cross reactivity of about $3.3 \%$ for $\operatorname{IgM}$ positivity with other viral infectious (EBV, measles, herpes simplex varicella- zoster influenza vaccine) (Maine et al., 2000). Although primary infection in any stage of pregnany presents a risk for intrauterine infection from 30-50\% but congenital infection in seropostive mothers is only from 0.2 to 1.5 percent, and that it needs more microbiological and histological confirmation (Stagno, 1990). The results of Tanaka et al., (2006) suggested that latent CMV infection predisposes to adverse pregnancy outcomes (Tanaka et al., 2006).

In comparison with other studies, we have these results: In a study which was performed by Munro et al. (2005), rate of CMV IgG seroprevalence in blood donors was shown to increase with age from (34.9$72.4 \%$ ) during 30 years but our study showed no relation between age and infection with CMV (Munro et al., 2005; Mathur et al., 1981). 
In our study the prevalence of seropositivity for CMV was higher than Western Europe, America and Australia (Munro et al., 2005) but our findings were similar to a study in China with prevalence $\mathrm{IgG}$ (95.67\%) in pregnant women (Guo 1992). In India serological surveys have shown that the prevalence of CMV antibodies in adult population is about $(80-90 \%)$ (Mukundan et al., 1977).

\section{CONCLUSION}

We can diagnose high risk pregnancy even with serological tests in areas with insufficient equipment, and in South of Iran most pregnant women were immune against primary CMV infection but some studies recommended that childbearing age women should be screened for CMV antibodies but we suggest that confirmation of congenital CMV infection is difficult in this area and also there is high immunity for CMV in pregnant women and congenital infection is rare in seropositive mothers (Collient et al., 2004), therefore we recommend pregnant women should be attentive of disease prevention guidelines on personal hygiene during pregnancy, especially hand washing after handling diapers or oral secretions. But we recommend high risk pregnant women for example: mothers that working in day care center or health care worker should be screened for CMV serological tests during pregnancy.

\section{ACKNOWLEDGEMENT}

This study was completely financed by Hormozgan University of Medical Sciences. The authors are grateful to the patients and the control individuals who accepted to enter this study.

\section{REFERENCES}

Bodeus, M., S. Feyder and P. Goubau, 1998. Avidity of $\mathrm{IgG}$ antibodies distinguishes primary from nonprimary cytomegalovirus infection in pregnant women. Clin. Diagn. Virol., 9: 9-16. PMID: 9562853

Boppana, S.B., R.F. Pass, W.J. Britt, S. Stagno and C.A. Alford, 1992. Symptomatic congenital cytomegalovirus infection: Neonatal morbidity and mortality. Pediatr. Infect. Dis. J., 11: 93-99. PMID: 1311066

Collient P., D. Subtil and N. Houfflin-Deberag, 2004. Routine CMV screening during pregnancy. Eur. J. Obstet. Gynecol. Reprod. Biol., 114 : 3-11. PMID: 15099862
Cook, S.M., K.S. Himebaugh and T.S. Frank, 1993. Absence of cytomegalovirus in gestational tissue in recurrent spontaneous abortion. Diagn. Mol. Pathol., 2: 116-119. PMID: 8269275

Dahle, A.J., K.B. Fowler, J.D. Wright, S.B. Boppana and W.J. Britt et al., 2000. Longitudinal investigation of hearing disorders in children with congenital cytomegalovirus. J. Am. Acad. Audiol., 11: 283-290. PMID: 10821506

Demmler, G.J., 1991. Infectious diseases society of America and centers for disease control: Summary of a workshop on surveillance for congenital cytomegalovirus disease. Rev. Infect. Dis., 13: 315-329. PMID: 1645882

Enders, G., U. Bader, L. Lindemann, G. Schalasta and A. Daiminger, 2001. Prenatal diagnosis of congenital cytomegalovirus infection in 189 pregnancies with known outcome. Prenat. Diagn., 21: 362-377. PMID: 11360277

Fowler, K.B., S. Stagno and R.F. Pass, 2003. Maternal immunity and prevention of congenital cytomegalovirus infection. J. Am. Med. Assoc., 289: 1008-1011. PMID: 12597753

Fowler, K.B. and S.B. Boppana, 2006. Congenital Cytomegalovirus (CMV) infection and hearing deficit. J. Clin. Virol., 35: 226-231. PMID: 16386462

Gaytant, M.A., E.A. Steegers, B.A. Semmekrot, H.M. Merkus and J.M. Galama, 2002. Congenital cytomegalovirus infection: Review of the epidemiology and outcome. Obstet. Gynecol. Surv., 57: 245-256. PMID: 11961482

Grangeot-Keros, L., M.J. Mayaux, P. Lebon, F. Freymuth and G. Eugene et al., 1997. Value of Cytomegalovirus (CMV) IgG avidity index for the diagnosis of primary CMV infection in pregnant women. J. Infect. Dis., 175: 944-946. PMID: 11961482

Guo, T., 1992. Study of primary CMV infection in pregnant women. Zhonghua Liu Xing Bing Xue Za Zhi., 3: 76-8. PMID: 1327533

Hagay, Z.J., G. Biran, A. Ornoy and E.A. Reece, 1996. Congenital cytomegalovirus infection: A longstanding problem still seeking a solution. Am. J. Obstet. Gynecol., 174: 241-245. PMID: 8572014

Hammouda, N.A., W.M. El-Gelbaly and S.M. Sadaka, 1993. Seroprevalence of toxoplasma and cytomegalovirus in complicated pregnancies. J. Egypt. Soc. Parasitol., 23: 865-70. PMID: 8308361

Lazzarotto, T., P. Spezzacatena, P. Pradelli, D.A. Abate and S. Varani et al., 1997. Cytomegalovirus during primary and secondary infections in immunocompetent and immunocompromised subjects. Avidity of immunoglobulin G directed against human. Lab. Immunol., 4: 469-473. PMID: 9220166 
Lazzarotto, T., L. Gabrielli and M. Lanari et al., 2004. Congenital cytomegalovirus infection. Hum. Immunol., 65: 410-415. PMID: 15172439

Luerti, M., A. Santini, O. Bernini, M. Castinglioni and M.C. Ragni, 1983. ELISA antibodies to cytomegalovirus in pregnant patients: Prevalence and correlation with spontaneous abortion. Biol. Res. Pregnancy Perinatol., 4: 181-183. PMID: 6317066

Maine, G.T., R. Stricker, M. Schuler, J. Spesard and S. Brojanac et al., 2000. Development and clinical evaluation of a recombinant-antigen-based cytomegalovirus immunoglobulin $\mathrm{M}$ automated immunoassay using the Abbott $\mathrm{A} \times \mathrm{SYM}$ analyzer. J. Clin. Microbiol., 38: 1476-1481. PMID: 10747129

Mathur, A., L. Jindal and V.C. Chaturvedi, 1981. A serological study of cytomegalovirus infection at Lucknow. Indian J. Med. Res., 73: 678-681. PMID: 6266952

Mukundan, P., M. Jadvan and T.J. John, 1977. Prevalence of cytomegalovirus antibody in young children in Vellore. Indian J. Med. Res., 65: 589-592. PMID: 200552

Munro, S.C., B. Hall and L.R. Whybin, 2005. Diagnosis of and screening for cytomegalovirus infection in pregnant women . J. Clin. Microbiol., 43: 4713-4718. PMID: 16207970

Nielsen, S.L., I. Sorensen and H.K. Andersen, 1988. Kinetics of specific immunoglobulins M, E, A, and $\mathrm{G}$ in congenital, primary, secondary cytomegalovirus infection studied by antibodycapture enzyme-linked immunosorbent assay. J. Clin. Microbiol., 26: 654-661. PMID: 2835388
Ross, D.S., S.C. Dollard, M. Victor, E. Sumartojo and M.J. Cannon, 2006. The epidemiology and prevention of congenital cytomegalovirus infection and disease: Activities of the centers for disease control and prevention workgroup. J. Women's Health, 15: 224-229. PMID: 16620180

Stagno, S., R.F. Pass, G.Cloud and W.J. Brid et al., 1986. Primary congenital cytomegalovirus infection in pregnancy: Incidence, transmission to fetus and clinical outcome. J. A. Med. Assoc., 256: 1904-1908. PMID: 3020324

Stagno S., 1990. Significance of cytomegaloviral infections in pregnancy and early childhood. Pediatr. Infect. Dis. J., 9: 763-764. PMID: 2172906

Tanaka, K., H. Yamada, M. Minami, S. Kataoka and K. Numazaki et al., 2006. Screening for vaginal shedding of cytomegalovirus in healthy pregnant women using real-time PCR: Correlation of CMV in the vagina and adverse outcome of pregnancy. $\mathrm{J}$. Med. Virol., 78: 757-9. PMID: 16628580

Wreghitt, T.G., E.L. Teare and O. Sule et al., 2003 Cytomegalovirus infection in immuno competent patients. Clin. Infect. Dis., 37: 1603-1606. PMID: 14689339 